
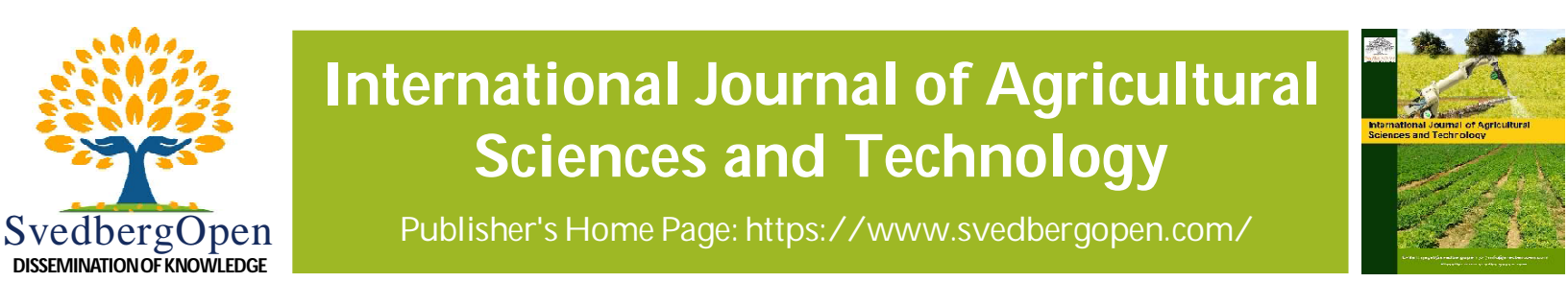

\title{
Ecological niche modeling to assessment of potential distribution of Neodiprion abietis (Harris, 1841) (Insecta, Hymenoptera, Diprionidae) in Eurasia
}

\author{
Konstantin Grebennikov ${ }^{1^{*}}$
}

1'All-Russian Plant Quarantine Centre, Moscow, Russia. E-mail: kgrebennikov@gmail.com

\section{Article Info}

Volume 1, Issue 1, February 2021

Received : 19 November 2020

Accepted : 15 January 2021

Published : 05 February 2021

doi: 10.51483/IJAGST.1.1.2021.1-7

\begin{abstract}
In the article first assesses the potential distribution in Eurasia of Neodiprion abietis (Harris, 1841) first time assessed. The species id a widely distributed in North America fir and spruce defoliator, intercepted in 2016 in the Netherlands. Analysis of the literature data on the known distribution and host plants of the species is given. Insufficient data for ecological modeling is shown, which causes a high degree of uncertainty in assessment of potential range. The results of modeling the potential range of the species using several algorithms are presented. The reliability of the obtained models and the importance of bio-climatic environmental variables for species distribution are assessed.

Keywords: Niche modeling, Potential distribution, Forest pests, Conifers, Neodiprion abietis

(C) 2021 International Journal of Agricultural Sciences and Technology. This is an open access article

under the CC BY license (https://creativecommons.org/licenses/by/4.0/), which permits unrestricted

use, distribution, and reproduction in any medium, provided you give appropriate credit to the original author(s) and the source, provide a link to the Creative Commons license, and indicate if changes were made.
\end{abstract}

\section{Introduction}

Neodiprion abietis (Harris, 1841) (Insecta, Hymenoptera, Diprionidae) is a serious pest of coniferous trees, widely distributed in North America from Canada to Mexico (GBIF 2020a), Neodiprion abietis (NEODAB) [World distribution]. The larvae of this sawfly cause defoliation (sometimes severe) of the host plants, which cause their weakening, decreasing growth, and sometimes tree death (Piene et al., 2001). The species has several ecological and geographical forms feeding on various fir and spruce species, including European spruce (Picea abies (L.) H.Karst.) (Knerer and Atwood, 1972). In autumn 2016, the cocoon N. abietis was detected in the Netherlands on branches of Gaultheria sp. imported from the USA. (Interception..., 2017). For this reason, in 2017 the species was included in the Alert list of the European and Mediterranean Plant Protection Organization. To assess the possibility of N. abietis acclimatization in the Old World, an attempt was made for the first time in this article to predict its potential distribution by the ecological niche modeling based on several algorithms.

\section{Materials and methods}

The source of data on the occurrences of N. abietis in North America were GBIF dataset (GBIF, 2020b). The distribution of potential host plants was reconstructed from various sources mentioned in the relevant section of the article. The free software openModeller desktop (de Souza Muñoz et al., 2011) version 1.1.0 and Maxent (Steven et al., 2020) version

\footnotetext{
* Corresponding author: Konstantin Grebennikov, All-Russian Plant Quarantine Centre, Moscow, Russia. E-mail: kgrebennikov@gmail.com
} 
3.4.1 were used for ecological niche modeling of the potential N. abietis distribution. Data on bioclimatic environmental variables were obtained from raster layers of WorldClim v. 2.1 representing average values of climate data for 1970-2000 (Fick and Hijmans, 2017). Data processing and mapping were performed in QGIS (QGIS.org), statistical analysis-in Microsoft Excel. Layers of administrative boundaries are based on GADM database (www.gadm.org) version 3.4. The results of the ecological niche modeling experiments and the original shape-files on which the figures for this article are based are available in the attached dataset.

\section{Results and discussion}

There is no doubt that the main factor limiting the distribution of phytophagous is the presence of host plants. Unfortunately, their exact list for N. abietis has not yet been identified. Various authors mentioned plants of the genus Abies, Picea, Tsuga, Pseudotsuga, Pinus and even Thuja as such (Bird, 1929). Ross (1955) identified the abietis complex in the sertifer group of the Neodiprion genus, including two species, one of which inhabits Abies and Picea, the other (not formally described) - Tsuga and Pseudotsuga. Knerer and Atwood in their description of biology "Neodiprion abietis Complex" (Knerer and Atwood, 1972) identified four forms ("strains"), among the host plants mentioned balsam fir (Abies balsamea (L.)), white fir (Abies concolor (Gordon) Lindley ex Hildebrand), white spruce (Picea glauca (Moench) Voss), black spruce (Picea mariana (Mill.) Britton, Sterns \& Poggenburg), European spruce (Picea abies (L.) H. Karst.). However, it cannot be said that these ecological and geographical diversity of the species is limited to these four forms. Moreover, the identity and limits of the $N$. abietis species need to be clarified, and all reports on findings of this species published in the $19^{\text {th }}$ and early $20^{\text {th }}$ centuries (before the description of closely related species and the revision of the genus prepared by Ross) should be considered critically. Due to the high uncertainty of the list of potential host plants of $N$. abietis, all species of the genus Abies and Picea are considered here as such. Reports on nutrition by plants of other genera are questionable, and most likely a mistake.

Data on host plant distribution in North America were obtained from clone of digital representations of tree species range maps from “Atlas of United States Trees” by Elbert L. Little, Jr. (Petry, 2020). Fir and spruce ranges within Europe were established with some approximation from "Tree species maps for Europe" (Brus et al., 2012) and "Chorological data for the main European woody species" (Caudullo et al., 2020). The distribution of these genera in Asia was reconstructed on the data from the "Agricultural Ecological Atlas of Russia and Neighboring Countries" (Afonin et al., 2008), maps of the USSR tree ranges (Sokolov et al., 1977), some other publications (Xiang et al., 2007; Lockwood et al., 2013), and occurrences from Abies and Picea (GBIF 2020c; 2020d). Further assessment of potential N. abietis distribution in Eurasia was made within the limits of this approximate host plant range.

To assess the representativeness of the GBIF data on the occurrences of $N$. abietis, a map was made, correlating these occurrences with the literature data on the regions for which the species was reported, and the distribution of the host plants (Figure 1).

From this map it is clear that the GBIF dataset covers only part of the N. abietis range. For this reason, all models of potential distribution based on it are quite approximate and have a high degree of uncertainty. In further assessment of the reliability of various models, it was taken into account how adequately they describe the current distribution of the species, taking into account the literature data.

To select environmental variables optimal for niche modeling, the values of 19 bioclimatic variables from WorldClim raster layers were obtained for each of 121 points of occurrences from GBIF. The statistical analysis has shown correlation between these variables inside the dataset. For further modeling, 13 variables with Pearson correlation coefficient between them being less than 0.8 were selected:

bio01 - Annual mean temperature;

bio02 - Mean diurnal range (Mean of monthly (max temp - min temp));

bio03 - Isothermality (BIO2/BIO7) $(\times 100)$;

bio05 - Max temperature of warmest month;

bio07 - Temperature annual range (BIO5-BIO6);

bio08 - Mean temperature of wettest quarter;

bio09 - Mean temperature of driest quarter;

bio10 - Mean temperature of warmest quarter

bio12 - Annual precipitation; 


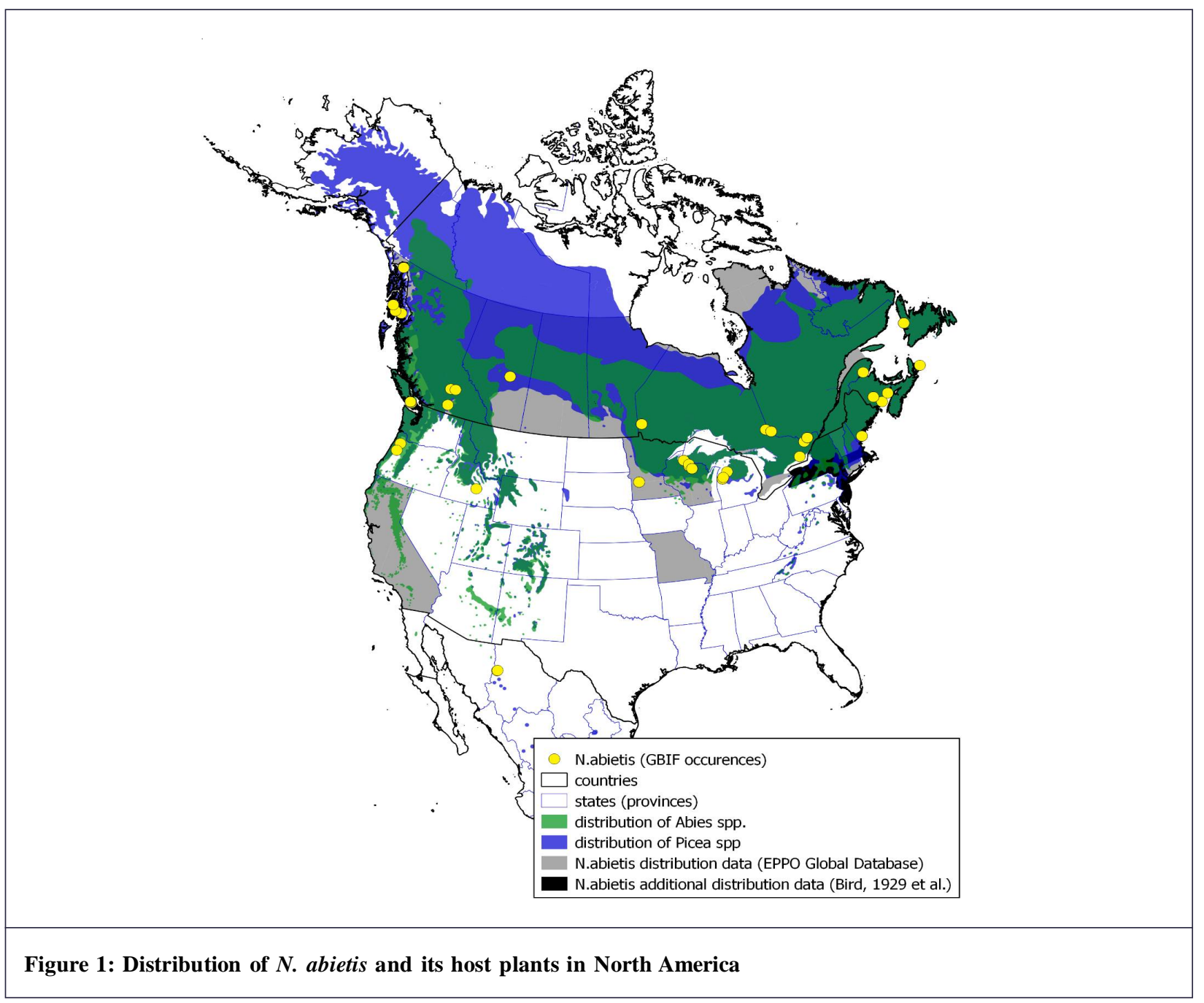

bio13 - Precipitation of wettest month;

bio15 - Precipitation seasonality (coefficient of variation);

bio17 - Precipitation of driest quarter;

bio18 - Precipitation of coldest quarter.

Based on these variables, four models of the potential range were constructed using algorithms:

1. Climate Space Model (openModeller desktop, with default settings, AUC = 0.927) (CSM);

2. Environmental Distance (openModeller desktop, with default settings, AUC = 0.999) (ED);

3. GARP with best subsets - DesktopGARP implementation (openModeller desktop, with default settings, AUC = 0.987) (GARP);

4. Maximum Entropy (Maxent, settings were determined experimentally by the maximum AUC value (feature types used: hinge, product, linear, threshold, quadratic; maximum background points: 50000; maximum iterations: 5000; default prevalence: 0.9), AUC = 0.989) (Maxent).

The results of the experiments for North America are shown in Figure 2:

The CSM and ED models appear to be insufficiently reliable (despite the high AUC value). The CSM indicates an extremely limited potential range, not even covering the occurrences of the original dataset. The ED, on the contrary, shows an extremely wide potential distribution going far into polar latitudes. Thus, the GARP and Maxent models that describe the current distribution of the species more adequately are more reliable. The GARP model assumes a somewhat more distant northward distribution of N. abietis, while the Maxent model, on the contrary, allows a greater southward distribution of the species. 


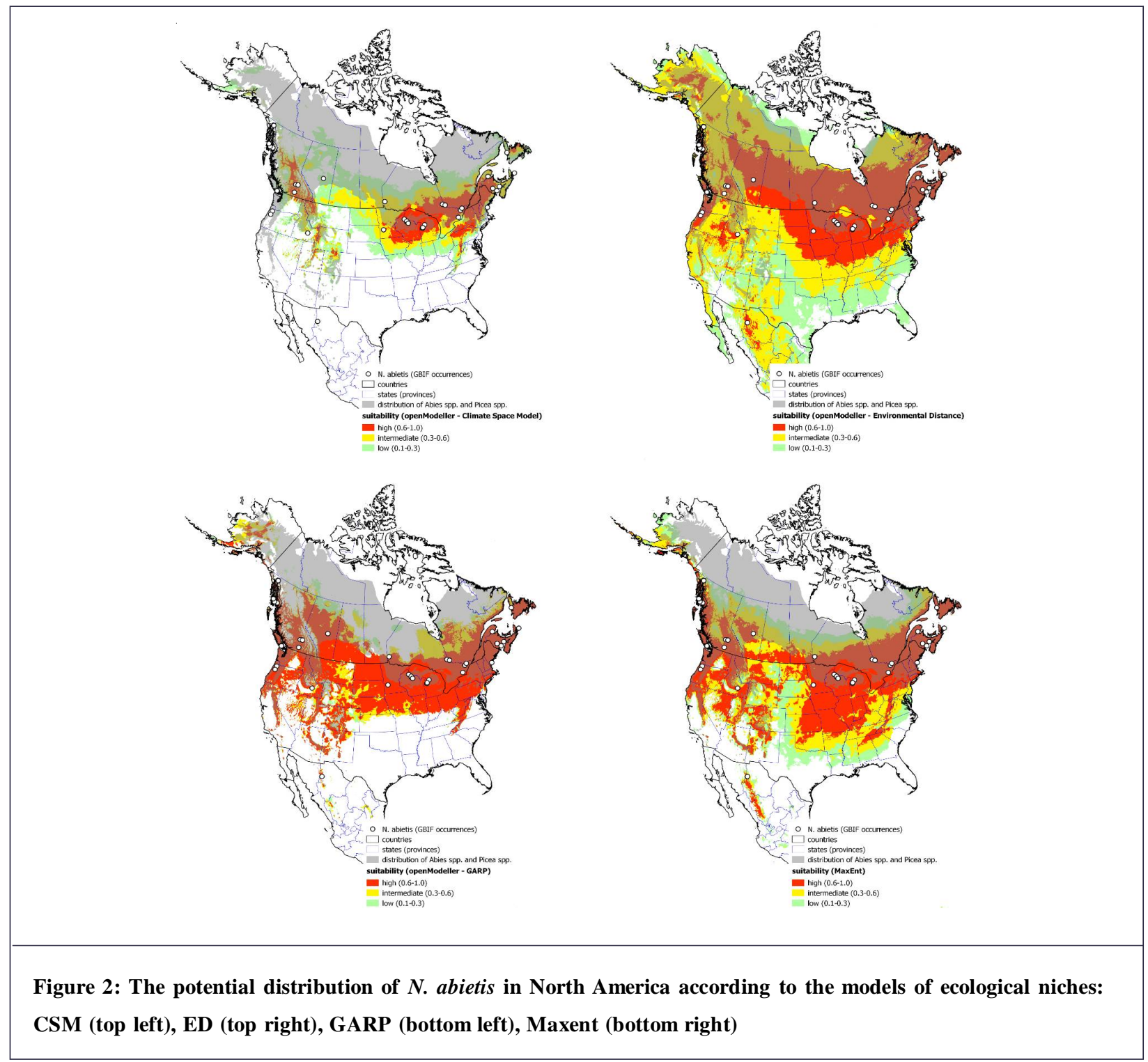

Extremely limited amount of georeferenced data on species distribution, and the doubtfulness of many references in the literature do not allow making a reasonable choice between these models. The high probability that the species will live in Missouri according to the Maxent model (where it is reported) can hardly be proof of greater reliability. The book (Craighead, 1950) referred to by EPPO Global Database provides only a general distribution of the species in eastern North America: "This species is widely distributed from Quebec to Manitoba in Canada, and in the United States from New England westward to Minnesota and Missouri”. N. abietis is also reported for Missouri by Ralf Bird (1929), but in the book to which he refers (Bureau of Entomology, 1908), there is only one mention of the species (on the page he indicated): "The fir sawfly (Lophyrus abietis Harris) defoliated much of the balsam fir on the islands and mainland along the coast of Maine." - That is, the reference (quoted in later literature) is actually to the state of Maine, not to Missouri. In addition, there are no natural fir or spruce forests in Missouri (Petry, 2020). All of these facts raise great doubts about the presence of $N$. abietis in this state.

Thus, the GARP model may be more reliable, but this can only be confirmed with more detailed data on the N. abietis distribution. At the moment, it is reasonable to consider both this model and Maxent to assess the potential distribution of the species. Figures 3 and 4 shows the potential distribution of N. abietis in Eurasia according to both models, and taking into account the distribution of plants from the genera Abies and Picea.

The figures above show that the models more or less similarly determine the possible distribution of $N$. abietis in the Old World. Only relative degrees of area suitability differ significantly. The assessment of the probability of the species' distribution in the territory of China also sharply differs: the GARP model assumes the possibility of wide distribution of $N$. abietis with high probability in many provinces, Maxent—almost everywhere mostly low probability of habitat, and other shape of the potential range. 


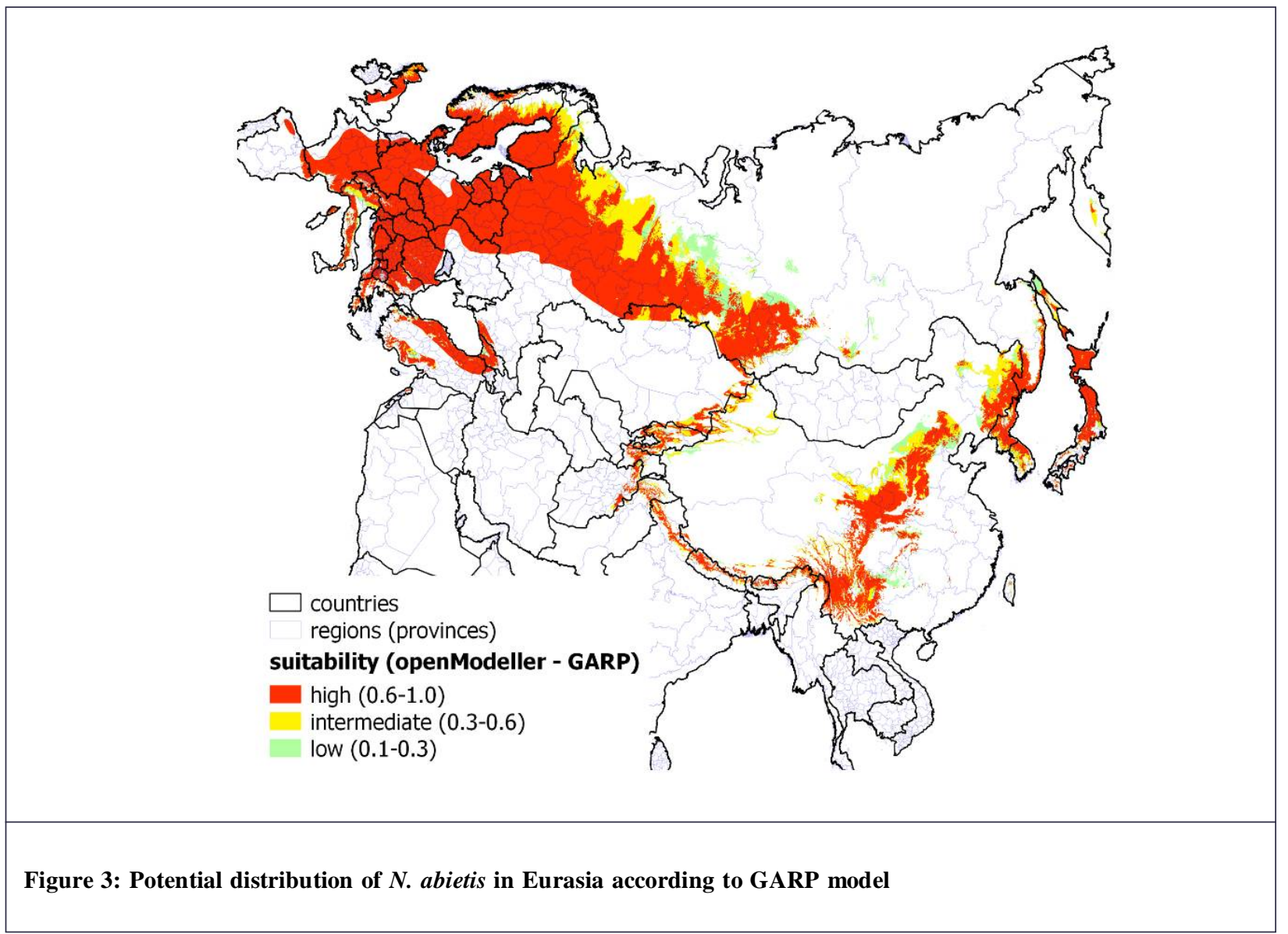

Jackknife resampling in Maxent (Figure 4) showed the greatest importance for modeling the variables bio01 (annual mean temperature), bio10 (mean temperature of warmest quarter), bio17 (precipitation of driest quarter) and bio05 (maximum temperature of warmest month).

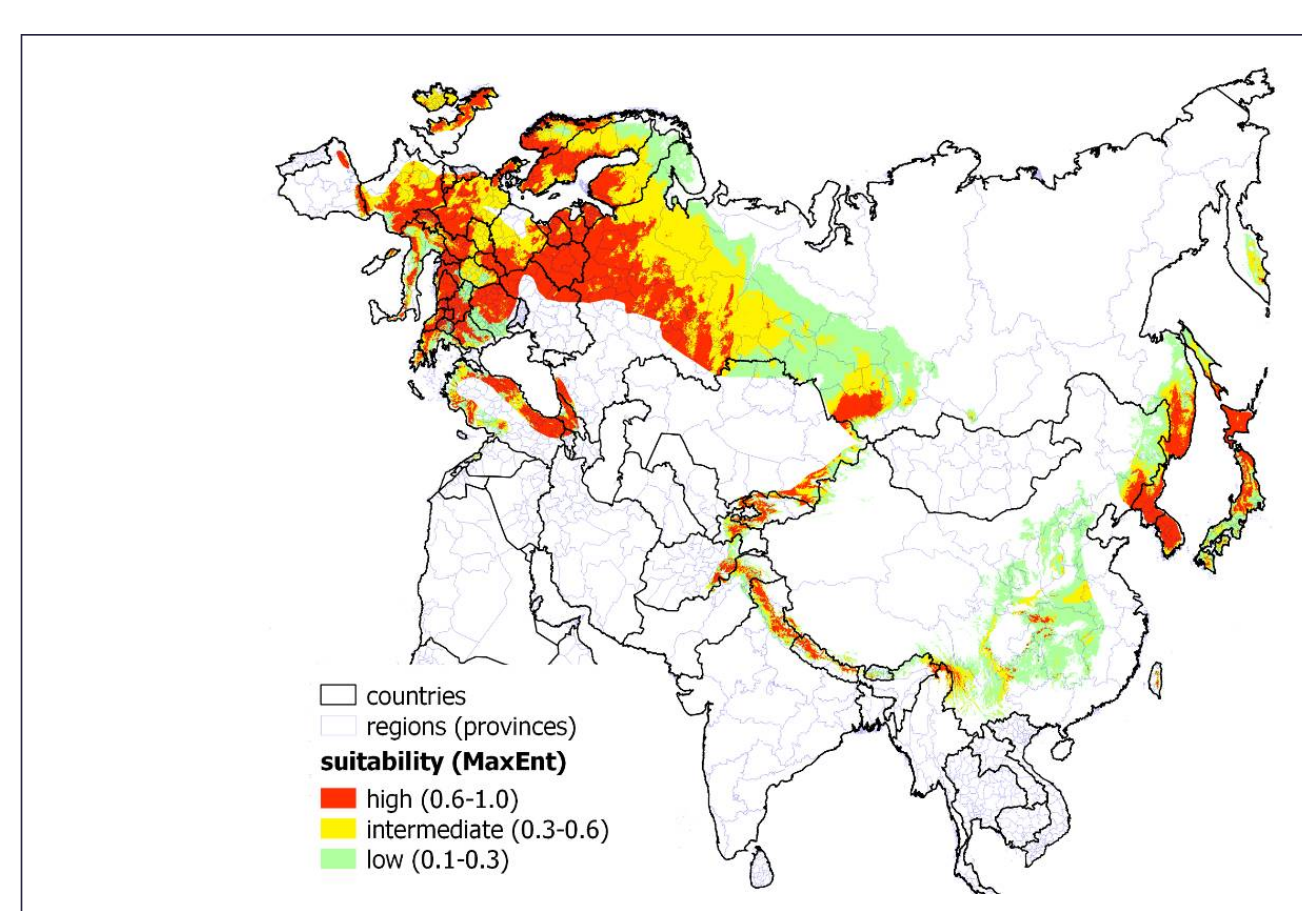

Figure 4: Potential distribution of N. abietis in Eurasia according to GARP Maxent model 
This suggests that the limits of the ecological niche of $N$. abietis are determined (besides the presence of host plants) by relatively low annual and maximum temperatures without noticeable dry periods. This is more or less consistent with the modern distribution of the species shown here, as well as models of the potential distribution.

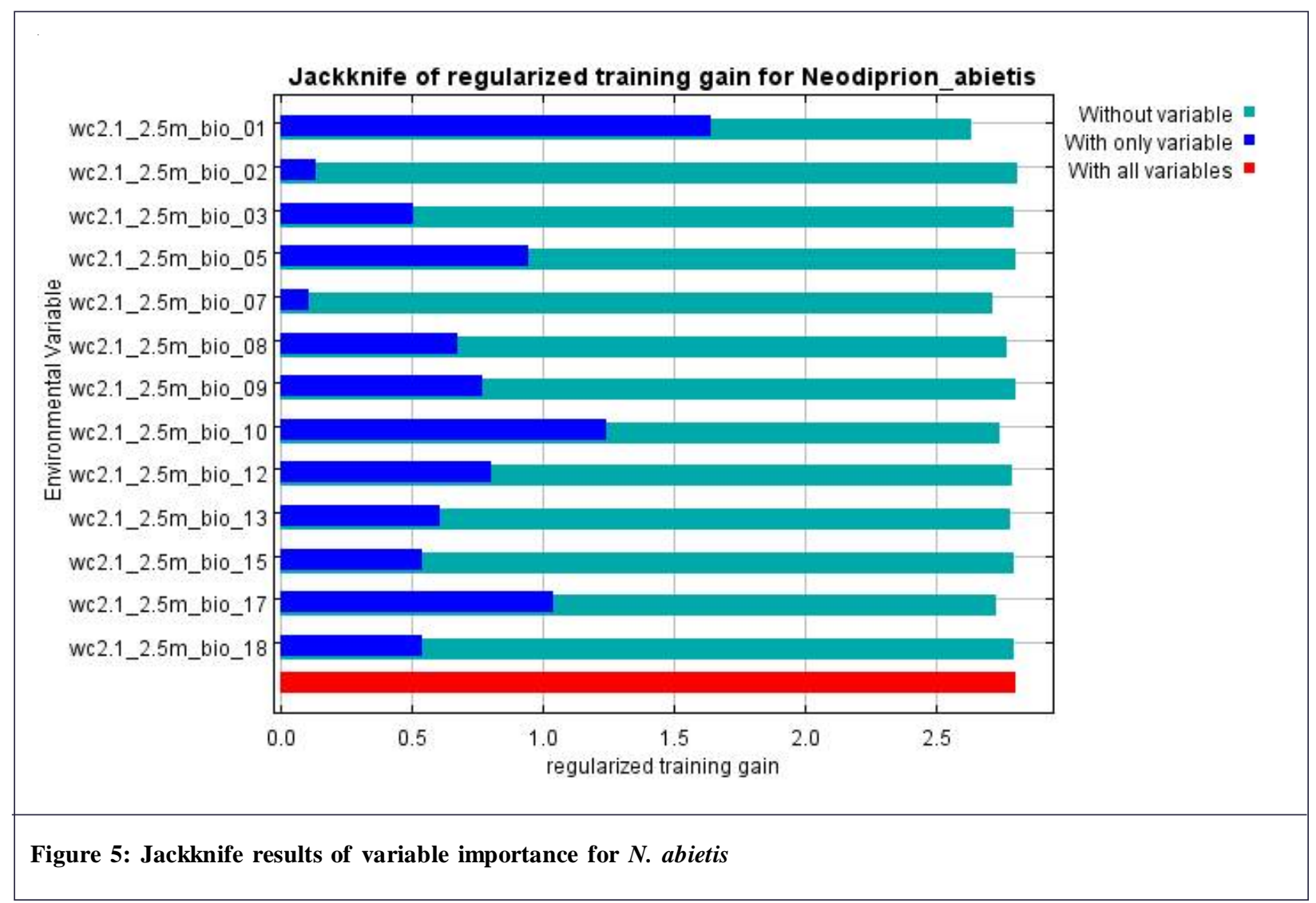

\section{Conclusion}

Modeling of the ecological niche of N. abietis showed a high probability of its distribution in Eurasia: most of Europe, Western Siberia, the Far East, Central Asia, the Himalayas, and possibly continental China. Due to the high uncertainty of both the list of host plants of the species and data on its current occurrence, the models shown for the potential distribution can only be considered as approximate. Indirect assessments suggest that models based on the genetic algorithm in openModeller and maximum entropy in Maxent are the most reliable. However, more accurate assessments are possible only on the basis of a more thorough study of the species in its natural range.

\section{References}

Afonin, A.N., Greene, S.L., Dzyubenko, N.I. and Frolov, A.N. (eds.) (2008). Interactive Agricultural Ecological Atlas of Russia and Neighboring Countries. Economic Plants and their Diseases, Pests and Weeds. http://www.agroatlas.ru

Bird, R. (1929). Notes on the fir sawfly Neodiprion abietis Harris. Proceedings of the Entomological Society of Ontario, 60, 76-82. https://www.biodiversitylibrary.org/item/151927\#page/9/mode/1up

Brus, D.J., Hengeveld, G.M., Walvoort, D.J.J., Goedhart, P.W., Heidema, A.H., Nabuurs, G.J. and Gunia, K. (2012). Statistical mapping of tree species over Europe. European Journal of Forest Research, 131(1), 145-157. https://doi.org/ $10.1007 / \mathrm{s} 10342-011-0513-5$

Bureau of Entomology. (1908). The principal injurious insects of the year 1908. In Yearbook of the United States Department of Agriculture (Vol. 1908). Govt. Print. Off.,. https://www.biodiversitylibrary.org/item/79066

Caudullo, G., Welk, E.and San-Miguel-Ayanz, J. (2020). Chorological data for the main European woody species. 10. https://doi.org/10.17632/hr5h2hcgg4.10

Craighead, F. C. (1950). Insect enemies of eastern forests. U.S. Dept. of Agriculture. https://www.biodiversitylibrary.org/ bibliography/65598 
de Souza Muñoz, M.E., De Giovanni, R., de Siqueira, M.F., Sutton, T., Brewer, P., Pereira, R.S., Canhos, D.A.L.and Canhos, V. P. (2011). OpenModeller: A generic approach to species' potential distribution modelling. GeoInformatica, 15(1), 111-135. https://doi.org/10.1007/s10707-009-0090-7

Fick, S.E. and Hijmans, R.J. (2017). WorldClim 2: new 1km spatial resolution climate surfaces for global land areas. International Journal of Climatology, 37(12), 4302-4315. https://doi.org/10.1002/joc.5086

GBIF (2020a). Neodiprion abietis (NEODAB) [World distribution] - EPPO Global Database. (2020) Retrieved on September, from https://gd.eppo.int/taxon/NEODAB/distribution

GBIF (2020b). GBIF Occurrence Download (Neodiprion abietis). (2020). Retrieved on September 22, 2020, from https:/ /www.gbif.org/occurrence/download/0030983-200613084148143

GBIF (2020c). GBIF Occurrence Download (Abies). (2020). Retrieved on September 22, 2020, from https://www.gbif.org/ occurrence/download/0030986-200613084148143

GBIF(2020d). GBIF Occurrence Download(Picea). (2020). Retrieved on September 22, 2020, from https://www.gbif.org/ occurrence/download/0066478-200613084148143

Interception of Neodiprion abietis in the Netherlands: addition to the EPPO Alert List (No. 2017/095; EPPO Reporting Service). (2017). https://gd.eppo.int/reporting/article-6063

Knerer, G. and Atwood, C.E. (1972). Evolutionary trends in the subsocial sawflies belonging to the Neodiprion abietis complex (Hymenoptera: Tenthredinoidea). Integrative and Comparative Biology, 12(3), 407-418. https://doi.org/ 10.1093/icb/12.3.407

Lockwood, J.D., Aleksiæ, J.M., Zou, J., Wang, J., Liu, J. and Renner, S.S. (2013). A new phylogeny for the genus Picea from plastid, mitochondrial, and nuclear sequences. Molecular Phylogenetics and Evolution, 69(3), 717-727. https://doi.org/10.1016/j.ympev.2013.07.004

Petry, W. (2020). wpetry/USTreeAtlas. https://github.com/wpetry/USTreeAtlas (Original work published 2017).

Piene, H., Ostaff, D.P. and Eveleigh, E.S. (2001). Growth loss and recovery following defoliation by the balsam fir sawfly in young, spaced balsam fir stands. The Canadian Entomologist, 133(5), 675-686. https://doi.org/10.4039/ Ent133675-5

QGIS.org, QGIS Geographic Information System. Open Source Geospatial Foundation Project. (2020). Retrieved September 22, 2020, from https://qgis.org/ru/site/

Ross, H.H. (1955). The taxonomy and evolution of the sawfly genus neodiprion. Forest Science, 1(3), 196-209. https:// doi.org/10.1093/forestscience/1.3.196

Sokolov, S.I., Svjaseva, O.A. and Kubli, V.A. (1977). Ranges of trees and shrubs of the USSR (Vol. 1). Nauka.

Steven, J. Ph., Schapire, R. E. and Dudík, M. (2020). Maxent software for modelling species niches and distributions (Version 3.4.1). Retrieved on September 22, 2020, from https://biodiversityinformatics.amnh.org/open_source/ maxent/

Xiang, X., Cao, M. and Zhou, Z. (2007). Fossil history and modern distribution of the genus Abies (Pinaceae). Frontiers of Forestry in China, 2(4), 355-365. https://doi.org/10.1007/s11461-007-0058-4

Cite this article as: Konstantin Grebennikov (2021). Ecological niche modeling to assessment of potential distribution of Neodiprion abietis (Harris, 1841) (Insecta, Hymenoptera, Diprionidae) in Eurasia. International Journal of Agricultural Sciences and Technology. 1(1), 1-7. doi: 10.51483/IJAGST.1.1.2021.1-7. 